\title{
Martian Glaciation and the Flow of Solid $\mathrm{CO}_{2}$
}

\author{
BRUCE R. CLARK AND ROSEMARY P. MULLIN \\ Department of Geology and Mineralogy, The University of Michigan, \\ Ann Arbor, Michigan, 48109
}

Received April 10, 1975

\begin{abstract}
'The flow law determined experimentally for solid $\mathrm{CO}_{2}$ establishes that a hypothesis of glacial flow of $\mathrm{CO}_{2}$ at the Martian poles is not physically unrealistic. Compression experiments carried out under 1 atm pressure and constant strain rate demonstrate that the strength of $\mathrm{CO}_{2}$ near its sublimation point is considerably less than the strength of water ice near its melting point. The data fit a power law "creep" equation of the form

$$
\dot{\epsilon}=\left(4 \times 10^{6}\right) \sigma^{3.9} \exp (-12200 / R T),
$$

where $\dot{\epsilon}$ is compressive strain rate ( $\sec ^{-1}$ ), $\sigma$ is compressive stress (bars), $R$ is the gas constant in calories per mole, and $T$ is absolute temperature. The exponent of $\sigma$ of 3.9 contrasts with a value near 3.1 for water ice, and indicates that the strain rate is somewhat more sensitive to stress for $\mathrm{CO}_{2}$ than for water. Likewise, the low activation energy for creep, $12200 \mathrm{cal} \mathrm{mole}^{-1}$, illustrates that $\mathrm{CO}_{2}$ is not highly sensitive to temperature and is thus likely to flow over a broad range of temperatures below its melting point. Strength values for $\mathrm{CO}_{2}$ are of the order of one-tenth to one-third the strength of ice under equivalent conditions.

A plausible glacial model for the Martian polar caps can be constructed and is helpful in explaining the unique character of the polar regions. $\mathrm{CO}_{2}$-rich layers deposited near the pole would have flowed outward laterally to relieve high internal shear stresses. The topography of the polar caps, the uniform layering of the layered deposits, and the general extent of the polar "sediments" could all be explained using this model. Flow of $\mathrm{CO}_{2}$ rather than water ice greatly reduces the problems with Martian glaciation. Nevertheless, problems do remain, in particular the large amounts of $\mathrm{CO}_{2}$ necessary, the need to increase vapor pressure and temperature with depth in the polar deposits, and the lack of good observational evidence of flow features. Within the limits of the present knowledge of surface conditions on Mars, $\mathrm{CO}_{2}$ glaciation appears to be a realistic alternate working hypothesis for the origin of the polar features.
\end{abstract}

\section{INTRODUCTION}

Our knowledge of the surficial features at both the north and south poles of Mars has expanded enormously since the Mariner 9 television cameras were directed toward the planet in 1971. Descriptive reviews of observations at the south pole by Murray et al. (1972) and at the north pole by Soderblom et al. (1973b) have led to a general belief that both polar regions are mantled by a unique group of "sediments." At the surface is a thin cap of permanent ice, presumably mostly water ice, which is

Copyright (C) 1976 by Academic Press, Inc. All rights of reproduction in any form reserved. Printed in Great Britain underlain by a deposit a few kilometers thick of sharply banded material of much greater areal extent than the permanent ice cap, and which in turn is underlain by a series of more nondescript deposits of even greater areal extent. In addition, the Mariner 9 cameras showed a variety of topographic features in the polar regions, including a lobate pattern of dark markings on the permanent ice cap, and terraced cliffs, channels, and pits on the other mantling deposits.

Two general hypotheses have been suggested for the origin of the polar features 
(Murray and Malin, 1973a; Cutts, 1973a, 1973b). Murray and Malin interpreted the dark markings as cliffs that are roughly concentric about the center or thickest part of the permanent ice cap and become consistently lower in elevation toward the equator. They envisioned the deposits as a series of plates (or dishes) of decreasing radius stacked one on top of another. They also suggested that the plates are offset due to polar wandering. The plates themselves would be composed of the thin laminae of the underlying layered deposits. In Cutts' (1973a) view, the layered materials were deposited subaerially, under very stable atmospheric conditions, as flat sheets extending over the entire polar regions, then incised by winds blowing off the poles in a spiral pattern leaving channels in the permanent ice. Thus he interpreted the

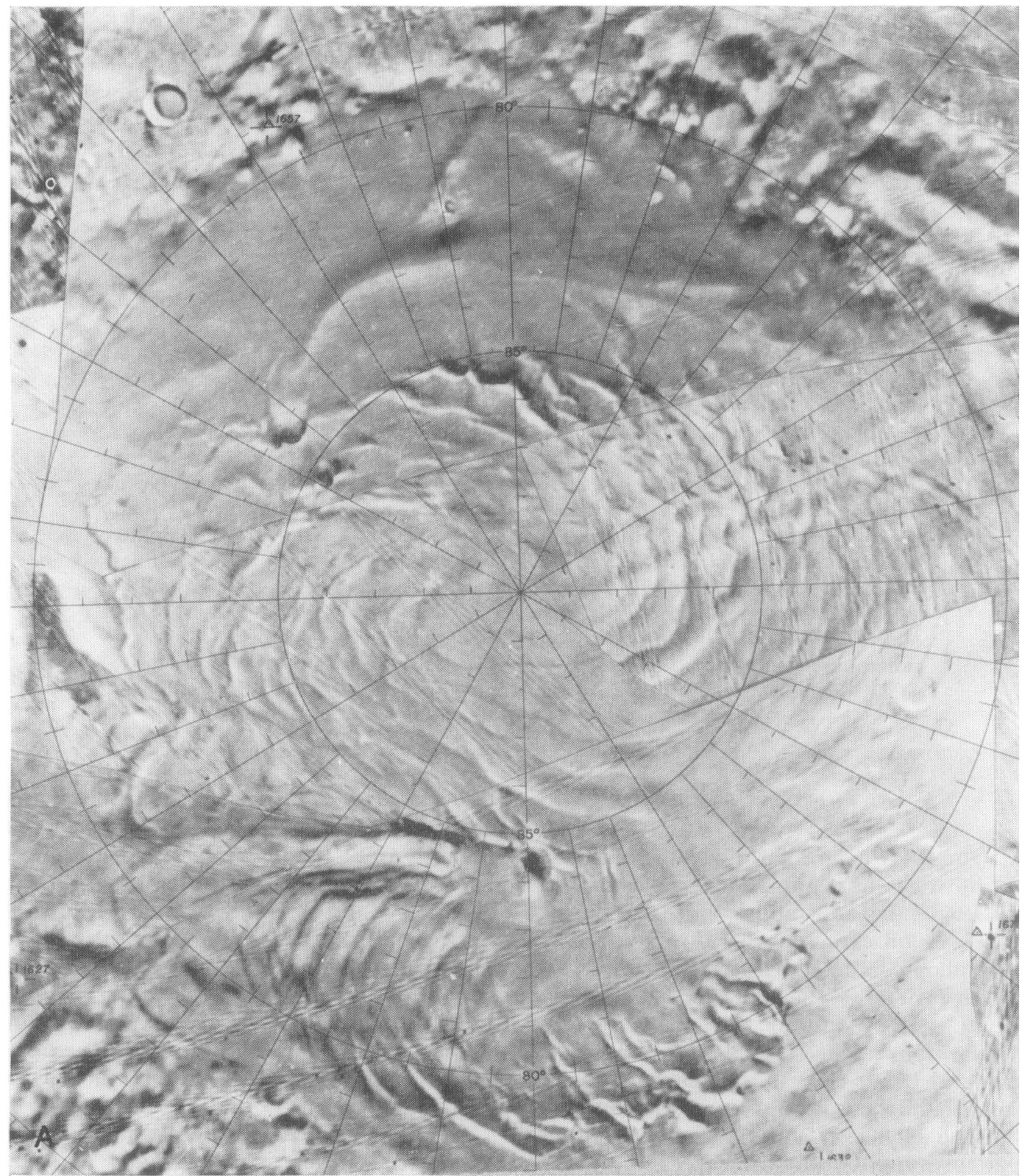


dark markings as erosional valleys rather than cliffs. The distinction between cliffs and channels is not obvious in the Mariner 9 pictures.

Both hypotheses have their drawbacks. Although Murray and Malin (1973a) attri- bute the markings to offsets in the location of sediment deposition due to polar wandering, the markings in the permanent ice cap at the two poles are not symmetrical (Cutts, 1973b). In fact the cap is a few degrees away from the rotation axis at the

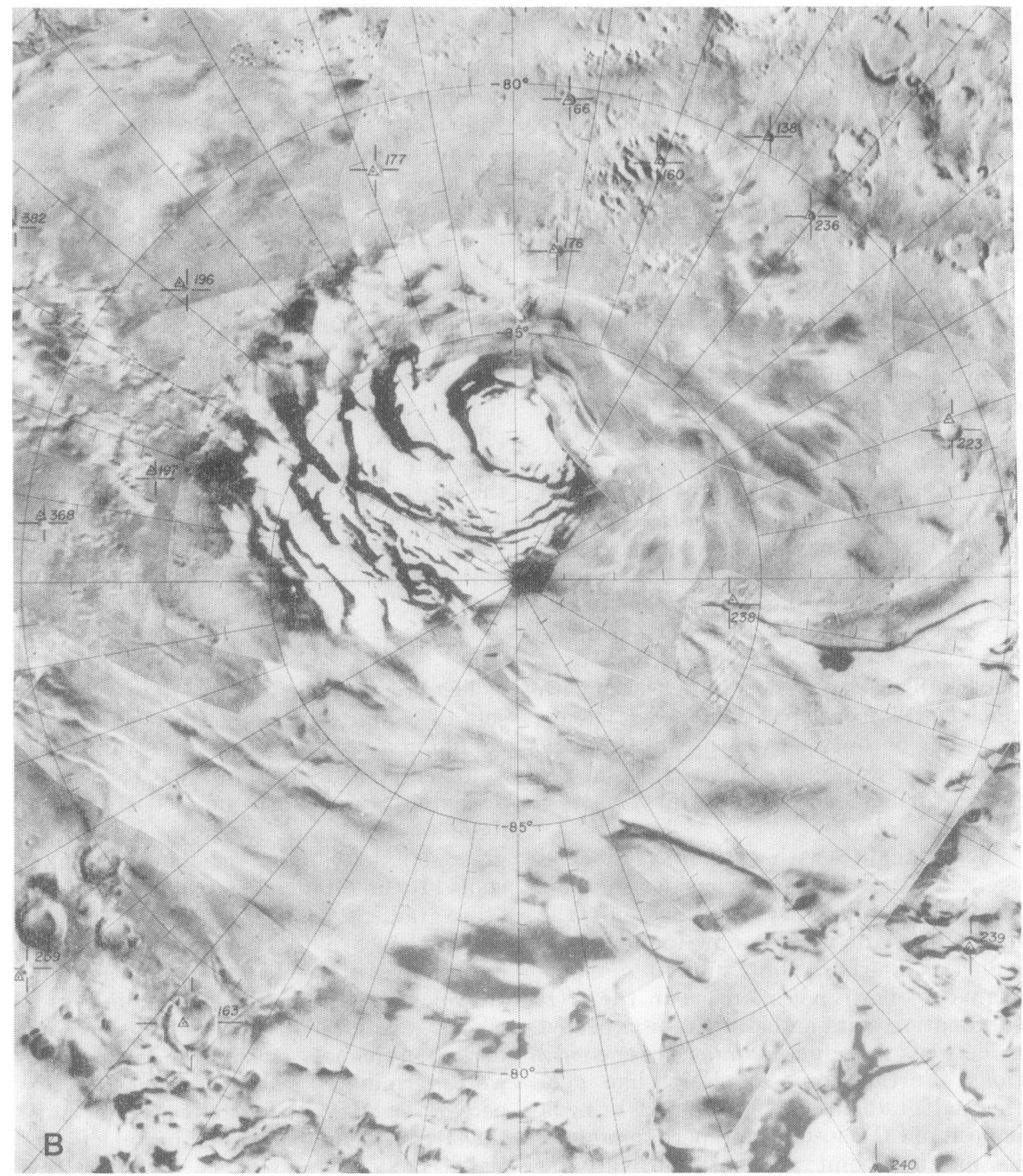

Fig. 1. Segments of the U.S. Geological Survey semi-controlled photomosaic of the north and south polar regions of Mars. (A) North polar region; high albedo of permanent cap has been reduced in preparation of photomosaic but permanent cap includes most of lobate pattern north of $80^{\circ}$ latitude. (B) South polar region; showing offset of permanent cap from the pole of rotation. 
south pole. Furthermore, Nash (1974) has shown that the planimetric regularity of the "cliff" edges (dark markings) is unrelated to their relative ages, suggesting that the edges are an erosional rather than a constructional feature. At the same time, Cutts' (1973a) interpretation of the markings as spiral features is at least disputable (for example, Dzurisin and Blasius, 1975). The markings clearly can be viewed as lobate and generally concentric about apparent centers of thick portions of the caps (Fig. 1). Although Cutts (1973a) cites strong evidence of erosion at work in the polar regions, the pattern of erosion need not be imprinted on the surface by a hypothetical wind pattern.

Observational features such as the dark markings and the generally concentric distribution of "sediments" at the poles, together with the unusually flat banding of the layered deposits, could be interpreted as evidence of lateral flow or "glacial" movements in the polar deposits. However, glaciers of water ice now or in the past on Mars seem unlikely indeed (Sharp, 1974). Present surface temperatures are far too low for ice to flow; the reduced Martian gravity requires great thicknesses of ice but almost no free water can be found; and the polar regions display a remarkable lack of features associated with glacial erosion or deposition on Earth (e.g., moraines or outwash features), although such features were suggested from the poorer-quality Mariners 6 and 7 photos (Belcher et al., 1971).

The diffculties with water ice as a glacial agent on Mars led us to consider the flow behavior of solid $\mathrm{CO}_{2}$. It is not only the most abundant volatile now found at the planetary surface, but present temperatures at both poles are near the $\mathrm{CO}_{2}$ sublimation point and it might be expected to be weak and ductile under these conditions. Furthermore, an Earth-like geothermal gradient on Mars could bring a deposit of $\mathrm{CO}_{2}$ close to, and perhaps above, its melting point at depth if overlying sediments raised the vapor pressure of buried $\mathrm{CO}_{2}$ (Sagan, 1973).

Because flow properties of $\mathrm{CO}_{2}$ had not previously been established, there was no physical basis for considering the possibility of $\mathrm{CO}_{2}$ glaciation or the types of features which might be produced by movement of $\mathrm{CO}_{2}$-rich materials. Sharp (1974) assumed that $\mathrm{CO}_{2}$ could not flow appreciably under Martian polar conditions. Murray et al. (1972) assumed that features such as craters which were partly buried by the blanket of laminated terrain should appear eroded by movements in the laminated terrain. Might $\mathrm{CO}_{2}$ behavior be sufficiently different from water ice behavior to produce different types of flow features?

To investigate these assumptions we have derived a flow law for solid $\mathrm{CO}_{2}$ from a series of laboratory deformation experiments. The flow law can be used to predict its behavior under conditions thought reasonable for the Martian polar regions. The flow strength of $\mathrm{CO}_{2}$ is so much less than that of water ice near its melting point (Glen, 1955), that we propose as an alternate working hypothesis a model for the history of the polar deposits which includes lateral flow of $\mathrm{CO}_{2}$-rich layers near the poles. Finally, we discuss assumptions and constraints required by such a model.

\section{Experimental Procedtre}

The flow law for $\mathrm{CO}_{2}$ was derived from sets of compression experiments at $1 \mathrm{~atm}$ confining pressure, constant strain rate, and temperatures from 163 to $193^{\circ} \mathrm{K}$. Jacketed samples of solid $\mathrm{CO}_{2}, 19 \mathrm{~mm}$ in diameter by $48 \mathrm{~mm}$ in length, were compressed axially in an insulated chamber cooled by liquid nitrogen (Fig. 2). Temperature gradients along the sample were kept to less than $3^{\circ} \mathrm{K}$ by cooling the upper and lower halves of the chamber independently. However, thermal drift of the unit as a whole was difficult to control for long periods of time. As a result, the experiments were terminated after strain of a few percent or less, but in each case, not until the stress-strain curves had become essentially flat. The evidence from a few extended tests indicated that strain hardening did not affect the strength values greatly, within the temperature and strain rate ranges used here. 


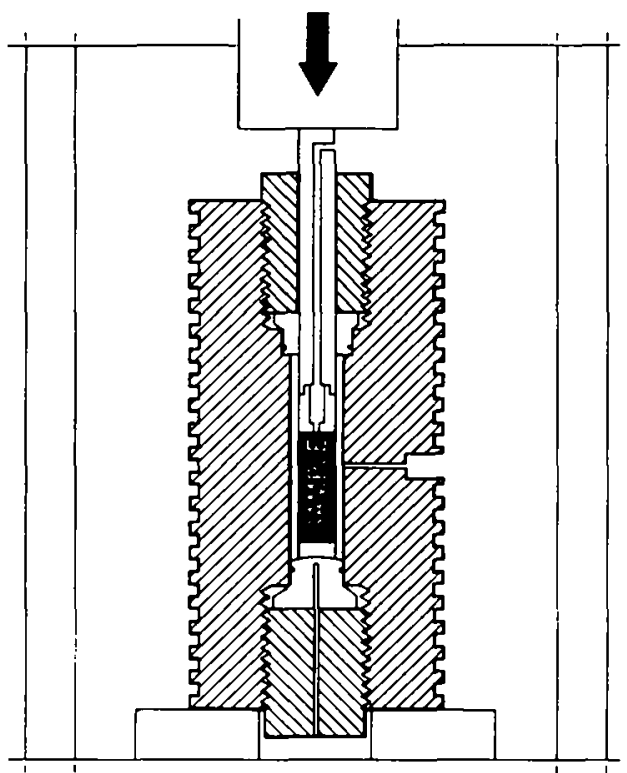

FIG. 2. Schematic drawing of aample chamber within hydraulic press. Although chamber is designed to test samples under high confining pressures, difficulties with sealing at very low temperatures have postponed those tests. Grooves on outside of chamber are pathways for liquid nitrogen coolant.

The $\mathrm{CO}_{2}$ samples were cored from large blocks of commercially prepared solid $\mathrm{CO}_{2}$. The blocks are formed by converting liquid $\mathrm{CO}_{2}$ to snow at low temperature, then compacting the snow under pressures as high as 150 bars. Minute amounts of propylene glycol $(0.02 \%)$ and oil $(0.001 \%)$ are added to the $\mathrm{CO}_{2}$ snow to increase the adhesion between grains, but the only other measurable impurity is a trace of water. The starting material has a texture of interlocked equidimensional grains of very uniform grain size, approximately $0.3 \mathrm{~mm}$ in diameter. Grain boundaries are smooth and simple. No pore spaces are visible even at magnifications of $40 \times$.

The authors did not attempt to investigate any of the $\mathrm{CO}_{2}$ clathrate compound suggested by Miller and Smythe (1970) as present in the Martian polar caps. Sharp (1974) assumes that only minor amounts of clathrate would be present, limited by an apparently severe shortage of available $\mathrm{H}_{2} \mathrm{O}$. The composition of volatile layers

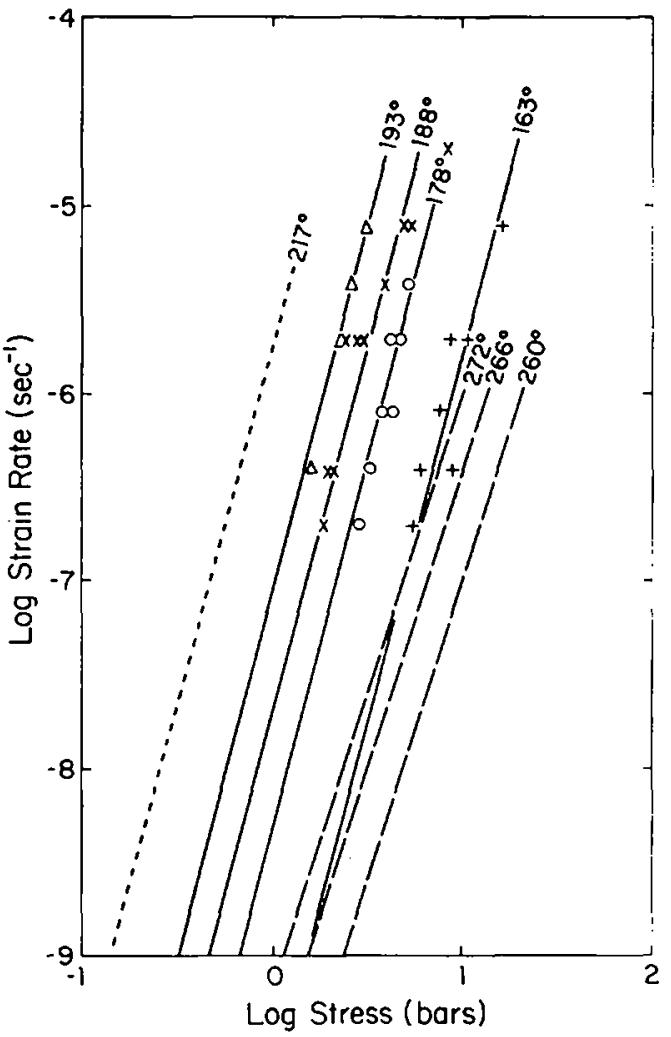

Fig. 3. Graph of $\mathrm{CO}_{2}$ compressive strength vs strain rate. Solid lines are straight lines fitted to data for $\mathbf{N}=3.9$. Dotted line at left is extrapolated to melting point of $\mathrm{CO}_{2}$. Dashed lines at right are data for water ice at temperatures given (from Glen, 1955).

beneath the surface of the polar cap remains open for speculation.

The results of the deformation experiments are plotted in Fig. 3 as a graph of the log of strength $\sigma$ vs the log of the strain rate $\dot{\epsilon}$ for a series of different temperatures. When plotted using these coordinates, the data for a single temperature appear to lie approximately along a straight line, although the range and accuracy of the points are not great enough to establish such a power-law relationship as the best-fitting law possible (see also Sherby and Burke, 1967). There is some suggestion from the $188^{\circ}$ data that the straight-line relationship does not hold. However, at other temperatures the fit is quite good, and the assumption of a power-law fit seems 
justified for extrapolation over only two orders of magnitude to hypothetical glacial strain rates $\left(10^{-9} \sec ^{-1}\right)$.

The fit of straight lines by least squares to all points for each temperature gives a relationship

$$
\log \dot{\epsilon} \propto N \log \sigma,
$$

where $N$ varies between 3.0 and 4.9 with a mean value of 3.9 . The scatter of $N$ is not temperature dependent and should be reduced if an expanded range of strain rates were tested. This value contrasts with values of $N$ for water ice found from creep tests (Glen, 1955) and from tunnel closure measurements (Nye, 1953) of 3.17 and 3.07 , respectively. Thus the strength of $\mathrm{CO}_{2}$ is somewhat less sensitive to strain rate than the strength of water ice.

The effect of temperature on $\mathrm{CO}_{2}$ strength is assumed to be of the commonly used form (Sherby and Burke, 1967)

$$
\dot{\epsilon} \propto \exp (-Q c / R T),
$$

where $Q c$ is the activation energy for creep. A plot of $\log \dot{\epsilon}$ vs $1000 / T$ is shown in Fig. 4, in which the slope of the line has the value $Q c /\left(2.3 \times 10^{3}\right) R$. The value of $Q c$ is found to be 12200 calmole $^{-1}$ from the experimental results. The activation energy for creep commonly can be correlated with activation energies for self-diffusion of atomic or molecular species, but to our knowledge no appropriate diffusion measurements have been made on solid $\mathrm{CO}_{2}$. The creep activation energy for $\mathrm{CO}_{2}$ is considerably smaller than that for water ice, given by Glen (1955) as $31800 \mathrm{cal}$ mole ${ }^{-1}$. Therefore the strength of $\mathrm{CO}_{2}$ is less affected by differences in temperature than the strength of water ice.

The flow law for solid $\mathrm{CO}_{2}$ is thus found experimentally to be

$$
\dot{\epsilon}=A \sigma^{3.9} \exp |12000 / R T|,
$$

from which strength at an appropriate strain rate and temperature can be predicted, and general comparisons with the behavior of water ice can be made (Fig. 3). An examination of the data in Fig. 3 shows that at temperatures within a few degrees

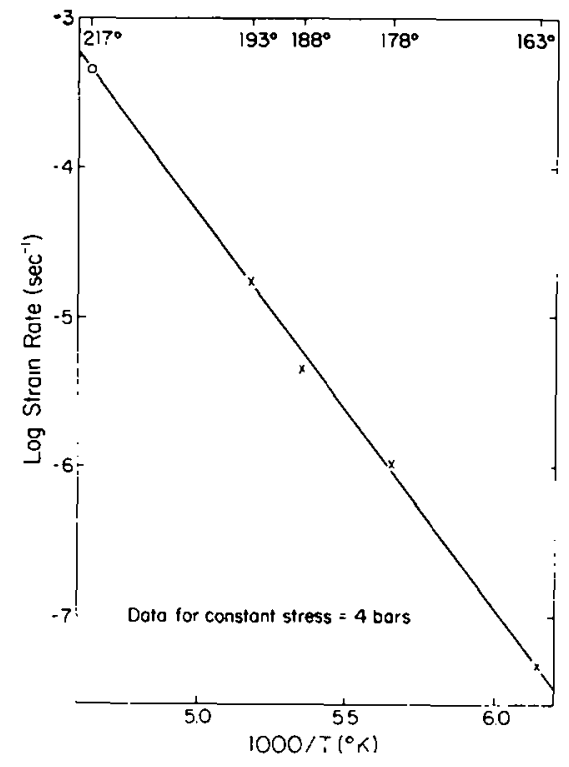

Fia. 4. Graph of strain rate vs $1000 / T$ for a constant stress of 4 bars. Points marked with $X$ are values determined from straight lines in Fig. 3. Point marked with o was used to extrapolate dotted line in Fig. 3.

of the respective melting/sublimation points, water ice is considerably stronger that solid $\mathrm{CO}_{2}$. At a strain rate of $10^{-7}$ $\mathrm{sec}^{-1}, \mathrm{CO}_{2}$ is one-fifth as strong, and even with the steeper slopes of the $\mathrm{CO}_{2}$ lines it would still be less than one-third as strong at a strain rate of $10^{-9} \mathrm{sec}^{-1}$.

If the pressure on buried $\mathrm{CO}_{2}$ rises to 5.1 bars (depth of burial of $<100 \mathrm{~m}$ ), then the temperature is free to rise to $217^{\circ} \mathrm{K}$ before the solid becomes unstable (melts). Under those conditions the flow law would predict $\mathrm{CO}_{2}$ strengths lying along the dotted line to the left of the solid lines in Fig. 3, giving a strength approximately one-tenth that of water ice near its melting point. As discussed below, such a situation can easily arise at depth at the Martian poles if pressures can rise above 5 bars, and temperatures follow a positive thermal gradient with depth.

Extrapolation of the flow law to buried conditions assumes that the flow law is independent of confining pressure. Rigsby (1958) showed that this was the case for water ice, and the flow laws for most other 
crystalline materials are also independent of confining pressures if brittle mechanisms are not active. No evidence of brittle mechanisms was observed in these experiments, either as drops in the stress values on the bulk stress-strain curves, or in the form of microfractures which could be observed in the binocular microscope. The latter might be expected to appear as either discrete breaks between or across grains or as a clouding of individual grains if fracturing were submicroscopic; however, at $40 \times$ magnification the grains appeared clear and unbroken. Nor was there any evidence, such as formation of visible porosity or opening of grain boundaries, that would indicate sliding had occurred along grain boundaries. Attempts to actually determine strengths under high confining pressures were postponed by difficulties with sealing the chamber at such low temperatures.

A second important assumption is that the proximity of the sublimation point to the experimental temperatures had no significant effect on the flow law. In other words, we presume that if we could raise the experimental temperature to the melting point $\left(\sim 217^{\circ} \mathrm{K}\right)$ without sublimation taking place, the flow law would still remain valid. Good evidence to support this assumption is found in the excellent fit of the points to the constant $Q c$ line in Fig. 4. Even within $2^{\circ} \mathrm{K}$ of the sublimation point, there is no suggestion that the activation energy is changed. Thus the flow law is assumed to be valid up to the melting point if sublimation could be eliminated, as it would be at higher pressures.

One difficulty in evaluating these assumptions is our present lack of knowledge of deformation mechanisms in $\mathrm{CO}_{2}$. The evidence that the material is deforming by intracrystalline mechanisms, probably translation gliding, is primarily the lack of features that appear to be due to cataclasis or brittle fracturing. Because of the facecentered cubic structure of $\mathrm{CO}_{2}$, the logical glide planes would be $\{111\}$, the closestpacked planes, and the glide direction $\langle 1 \overline{1} 0\rangle$, which gives the shortest displacements. However, the arrangement of the elongate $\mathrm{CO}_{2}$ molecules in the struc- ture results in complex interference between oxygen atoms during slip on these planes. This produces unknown effects on the Peierls energy, and we have as yet no optical evidence of that glide law.

\section{Discussion}

The low resistance of solid $\mathrm{CO}_{2}$ to shear stresses, as described by the laboratory flow law, adds an important constraint to speculation about the character and origin of the deposits of the Martian polar regions. If a convincing case can be made that the polar deposits have not flowed, then one of the following conclusions seems likely. (a) There has never been a large volume of solid $\mathrm{CO}_{2}$ deposited at the poles; (b) a large volume of solid $\mathrm{CO}_{2}$ may be present at the poles, but was deposited in the form of broad flat layers; (c) thick deposits of $\mathrm{CO}_{2}$ may have been present but were laterally confined and thus unable to flow; or (d) thick deposits have been present in the past only when the mean annual temperature was so low $\left(\sim 160^{\circ} \mathrm{K}\right)$ that flow was prohibited. The present hypotheses generally conform to (a) or (b) above and we emphasize that the flow law does not seriously jeopardize those views. In fact, the $\mathrm{CO}_{2}$ reservoir suggested by Murray and Malin (1973b) is restricted in shape to a broad thin sheet more effectively by the flow law than by atmospheric equilibrium considerations (which do not limit its downward extent).

If, on the other hand, the case against glaciation is not conclusive, then some type of glacial model might well account for the observations at the poles. Such an alternate working hypothesis should not be discounted until disproved. On the basis of the observations from Mariner 9 experiments, we contend that a glacial model, in which solid $\mathrm{CO}_{2}$ is the glacial agent, is plausible. In the following discussion we present one model which seems to fit the present observations. We emphasize that there is no compelling evidence that this (or some other) $\mathrm{CO}_{2}$ glacial hypothesis is correct. But strong arguments against water ice glaciers are not particularly 
valid for solid $\mathrm{CO}_{2}$, and thus the model remains a tenable one.

\section{Stratigraphy of the Polar Region}

Detailed descriptions of observations from Mariner 9 photographs have been presented by Murray et al. (1972) for the south polar region and by Soderblom et al. $(1973 b)$ for the north polar region. The generally accepted view is that away from the equatorial region, especially at latitudes greater than $70^{\circ}$, the cratered terrain covering most of the planet is overlain by a mantle of sedimentary deposits whose surfaces are pitted, etched, rippled, or smooth (Soderblom et al., 1973a). This mantle is in turn overlain by the layered deposits, which at the north pole cover most of the surface north of $80^{\circ}$ latitude, and at the south pole are distributed somewhat more irregularly from $-70^{\circ}$ to the south pole. Overlying the layered deposits are regions of permanent ice, mostly north of $80^{\circ}$ at the north pole, and offset somewhat from the pole but mostly south of $-85^{\circ}$ at the south pole (Fig. 1). The permanent ice cap is cut by dark markings in which ice is absent and underlying layered deposits are exposed. The markings are either outward-facing slopes, or actual channels (Dzurisin and Blasius, 1975), interpreted by Blasius (1973) to be on the order of $200 \mathrm{~m}$ deep. Annual frost deposits a few meters thick or less cover most of the layered deposits and permanent ice during the winter at each pole, respectively.

This stratigraphy is compiled into a highly schematic cross section in Fig. 5A. The units of most interest in this paper, the permanent ice and layered deposits, are shown in the enlarged schematic cross section, Fig. 5B. The vertical scale has been greatly expanded to show more detail.

The permanent ice appears to form a thin deposit overlying the layered terrain at each pole. If Blasius' (1973) estimate of relief on the caps is correct, the permanent ice must be less than $200 \mathrm{~m}$ thick, since in the topographic low regions the underlying layered deposits are exposed. Murray et al. (1972) and Soderblom et al. (1973b) interpret this deposit to be primarily water ice. If the winter frost is $\mathrm{CO}_{2}$, then disappearance of the frost during the Martian spring requires that solar insolation be great enough for sublimation of $\mathrm{CO}_{2}$. Yet during the summer months the shape of the permanent ice remains remarkably stable.

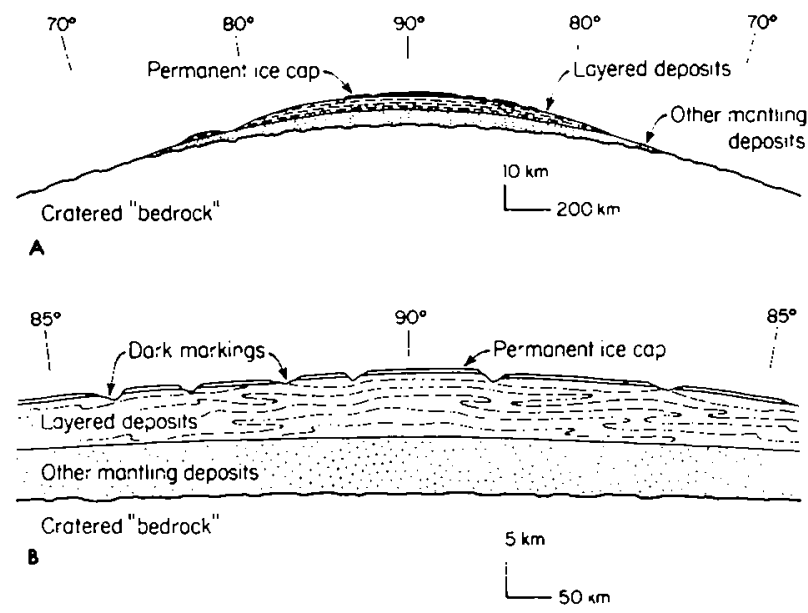

Fic. 5. Schematic cross sections depicting proposed stratigraphy and structure of Martian polar deposits. (A) General sequence of permanent ice, layered deposits, and other mantling deposits overlying highly cratored terrain. (B) Enlarged view of polar deposits showing a plausible flow pattern in the layered deposits, which could be responsible for breaks in the permanent ice cap, but would not be visible un Mariner 9 television pictures. 
The permanent ice must then be a residual deposit, containing water deposited at various times at the poles, then left behind as the more volatile $\mathrm{CO}_{2}$ sublimates.

The layered deposits were also observed in both south and north polar regions (Murray et al., 1972; Soderblom et al., $1973 \mathrm{~b})$. In both regions they are characterized by thin uniform layers that extend for hundreds of kilometers without disruption. The layers must be nearly horizontal and of the order of tens of meters thick. Good evidence is found in the Mariner 9 pictures that this deposit overlies the chaotic, pitted, or smooth plains of sediments that cover nearly all of the higher latitudes. Large outliers of the layered deposits in the form of buttes or tablelands are found at the edges of the deposits. It is difficult to imagine any history for these materials that does not end with an erosional stage to produce the present topographic relief. Cutts (1973a) makes a strong case for the importance of wind erosion in the polar region and this surely seems the most likely explanation for the present topography. But what of the origin of the deposits? A sequence a few kilometers thick and a thousand kilometers in diameter made up of a hundred regular layers each $20-30 \mathrm{~m}$ thick is a monumental task for any subaerial depositional agent. Cutts (1973b) speculates that a period of $10^{8} \mathrm{yr}$ of deposition of sediments from the atmosphere might be required to account for the layered deposits. Yet this requires a nearly complete absence of the wind conditions that lead to channeling and erosion at the poles today. In other words, dust storms such as the planet experienced in 1971 could not be responsible, since presumably the present atmosphere is far more effective at eroding the polar regions than building them up. In fact, it is difficult to conceive of such flat continuous layering in sediments that were not deposited under water. We suggest that it might be possible for much more irregular deposits to develop such flat regular banding during outward flow from the central polar regions before the present erosional stage. In this process the total thickness of deposits would decrease, the lateral extent would increase, and irregularities and discontinuities would be flattened until unrecognizable on the scale of the Mariner 9 pictures. The composition of the layered deposits is not known, but surface topographic features reported by Cutts (1974), as well as etch pit features described by Sharp (1973) from the other mantling deposits, indicate that volatiles may have been buried and then recently evaporated, leaving behind the strangely "eroded" topography.

Topographic features such as moraines and outwash plains are commonly associated with glaciers on Earth, but they appear to be virtually absent on Mars. The lack of outwash deposits might be expected from the high volatility of $\mathrm{CO}_{2}$ under low atmospheric pressures; free-running liquid $\mathrm{CO}_{2}$ on the Martian surface would require atmospheric pressures higher than 5 bars, a condition that would seem extremely unlikely. Consequently, little or no material could be moved by liquid $\mathrm{CO}_{2}$ "stream action," even at the edges of the flowing deposits. Likewise, although moraines might be expected to build up locally at the edges of the flowing deposits, two factors can account for their lack of development. First, because the basal sliding mechanism, so important in water ice glacier flow, does not operate in $\mathrm{CO}_{2}$ glaciers, there is little supply of excess material due to the gouging out of underlying material. Second, when small deposits of excess dust do form at the margins of the flowing material, wind action may be highly effective in removing the developing "moraine."

If $\mathrm{CO}_{2}$ is able to flow under Martian polar conditions, then we should investigate the possibility that outward flow of $\mathrm{CO}_{2}$-rich "ice sheets" from the poles may be responsible for (a) the dark markings in the permanent ice cap, (b) the very flat regular banding of the layered deposits, (c) the apparent ridge and channel topography on the layered deposits themselves away from the cap, (d) the general shape and location of the layered deposits, and (e) the lack of visible impact craters in the polar regions. In the following section we speculate on one type of $\mathrm{CO}_{2}$ model which seems plausible and can account for these features. 


\section{Plausible $\mathrm{CO}_{2}$ "Glacial" Model}

A "glacial" model for the origin of Martian polar features is based on the hypothesis that a much thicker sequence of "sediments" than is now present, including both dust and substantial quantities of $\mathrm{CO}_{2}$, was deposited at the very high latitudes at both poles. This weak pile of material began to settle under its own weight and flow laterally away from the poles until the internal shear stresses due to the great thickness of the deposit were reduced to a level that could be supported by the strength of the material. The thickness of the original pile might have been as much as $10-15 \mathrm{~km}$ but has been reduced by lateral flow to a maximum thickness of $5 \mathrm{~km}$ or less, with perhaps an average thickness of $2 \mathrm{~km}$, as estimated by Cutts (1973b). That $\mathrm{CO}_{2}$ could remain stable throughout such a thick sequence requires the assumptions (see next section) that the vapor pressure increases with burial, allowing solid $\mathrm{CO}_{2}$ to be stable to $217^{\circ} \mathrm{K}$ (triple point temperature); and that accumulation of the thick deposit would take place rapidly enough that the temperature would remain below $217^{\circ} \mathrm{K}$ even at depths of $10-15 \mathrm{~km}$ on a planet where the thermal gradient was probably positive with depth.

The present extent and thickness of the layered deposits are in good agreement with a roughly "equilibrium shape" for $\mathrm{CO}_{2}$-rich materials on Mars. The concept of an equilibrium shape is borrowed from the physics of water-ice glaciers and was derived in simplified form by Orowan (I949):

$$
H=(2 \tau L / \rho g)^{\frac{1}{2}},
$$

where $H$ is the thickness of the sheet at its center, $r$ is the shear strength, $L$ is the halfwidth (nearly equivalent to the radius of a circular sheet), $\rho$ is the density, and $g$ the gravitational attraction. We can choose a conservatively large value of $\tau=0.3 \mathrm{bars}$ at a strain rate of $10^{-9} \mathrm{sec}^{-1}$ from the flow law, recognizing that

$$
\tau=\sigma / \sqrt{ } 3,
$$

where $\sigma$ is the compressive stress (Nye, 1953). For a sheet of $1000 \mathrm{~km}$ radius on a flat base, the "equilibrium" thickness at the center would be $3.1 \mathrm{~km}$, in good agreement with estimates of present thicknesses. The sheet is not in true equilibrium of course, unless it could be shown that there is some fundamental strength to $\mathrm{CO}_{2}$, below which no flow at all would occur. However, as the stresses decrease internally, the flow rate decreases to the level where the amount of flow becomes negligible.

A lateral flow mechanism thus explains the present thickness and areal extent of the layered deposits effectively. However, it could be argued that deposition could fortuitously produce the overall shape of the layered deposits, and this shape evidence is hardly diagnostic of a flow origin.

The dark markings of the present surface also might be a reflection of lateral flow. Irregularities of surface topography are a logical corollary of such flow, and the patterns we see are the predicted ones: lobate in planimetric form, and generally concentric about the center or thickest parts of the deposits (Fig. 1). The markings themselves might have arisen in the following way. As wavelike flow at depth produced the irregular topography at the surface, the slopes facing toward the equator received a greater solar flux than the pole-facing slopes and became areas of sublimation or nondeposition of the water or solid $\mathrm{CO}_{2}$ that constitutes the permanent ice cap. As frost accumulated on other parts of the cap, the difference in temperature between frosted and frostfree areas was sufficient to control wind patterns over the polar cap, and selectively erode the frost-free areas. Erosion would be aided by local sublimation of volatiles in the dark regions heated by the higher solar flux. Thus the present topographic relief is an erosional feature as advocated by Cutts (1973b), but the planimetric pattern would be caused by the irregular topography left behind by flow within the underlying layered deposits. If the present erosional climate were to change, then the steep slopes and deep channels would close, assuming $\mathrm{CO}_{2}$ is still present in the layered deposits. However, 
erosion appears to be rapid enough to more than offset any slow $\mathrm{CO}_{2}$ flow.

There is also the possibility that the present dark markings are at least in part due to very recent movement of the deposits beneath the permanent ice cap, and that at least some of the dark markings are openings produced by pulling the superficial cap layer apart. This seems especially likely at the south pole where crevasse-like features appear toward the outer edges of the cap. Such an interpretation implies that the layered deposits still contain significant amounts of $\mathrm{CO}_{2}$.

As Cutts (1973a) argued, some small surface features visible on the layered deposits beyond the permanent ice are likely to be due to wind action. He cited examples of apparent dunes, fine grooving and fluting, and evidence for local redistribution of surface materials. However, much larger markings that appear to be escarpments are so similar to the pattern of dark markings on the permanent cap, especially at the south pole, that we interpret this pattern to be a continuation of the dark markings and also due to flow.

Finally, we consider the possibility that the strong banding of the layered deposits is a type of flow banding which originated during lateral flow of the deposits and greatly modified the original bedding. In view of the difficulties associated with producing such perfect layering by subaerial deposition, it seems reasonable to consider the possibility that the present banding was produced by a flow-related mechanism. Here we suggest that during flattening of the polar deposits, the lateral flow was mostly laminar, and perhaps confined to layers of nearly pure $\mathrm{CO}_{2}$. Alternate layers of dust were carried essentially passively with the $\mathrm{CO}_{2}$. Where flow was not exactly parallel with initial layering, isoclinal folds and transposition structures might have resulted, although none has yet been observed at a scale visible in the Mariner 9 pictures. Irregularities in the original sediments, such as channel fillings or impact craters, would be greatly reduced in the process of spreading and thinning the deposit as a whole. In fact the present material may be capable of "healing" itself by flow after meteorites strike the surface.

A flow-banded deposit might differ from a sedimentary deposit either by containing progressively thinner layers toward its base, due to greater amounts of flattening in the deeper parts, or by becoming reasonably complex and distorted at the edges, while sediments might merely become thinner until they disappear. The photographic evidence is not diagnostic; the true outer limits of the layered deposits have apparently been removed by erosion (Cutts, 1973b), and the critical features may no longer be available for observation.

In summary, we maintain that a plausible model involving "glacial" flow of $\mathrm{CO}_{2}$-rich layers in the Martian polar regions can be constructed and can provide an explanation of the overall shape, thickness, and extent of the layered deposits, of the presence of dark markings within the permanent ice caps and undulating topography beyond the edges of the ice caps, and of the persistent nearly horizontal uniform layering seen especially well in the layered deposits at the south pole. The observational evidence favoring such an interpretation is not strong from the Mariner 9 television pictures, but neither is the evidence against it. Perhaps the most effective arguments against $\mathrm{CO}_{2}$ flow could be made about the physical assumptions of the model rather than our present level of observation.

\section{Assumptions of a "Glacial" Model}

A "glacial" interpretation of Martian polar features does require some critical assumptions with far-reaching consequences. Previously, the most important assumption has been that the flow strength of $\mathrm{CO}_{2}$ is sufficiently high that it was unlikely to be a "glacial" agent. This has been shown to be incorrect. In this section we examine other important requirements the "glacial" model must satisfy.

First, it is necessary to postulate a sufficient amount of $\mathrm{CO}_{2}$ present in the layered deposits to allow them to move. We assume that the deposit could move easily if composed of approximately $50 \%$ 
$\mathrm{CO}_{2}$. Most of the volatiles would be located in fairly pure layers alternating with layers of nearly pure dust or fine sediment. Following the experiments on water icesand mixtures of Hooke et al. (1972), we expect the effects on strength of mixing dust with the solid $\mathrm{CO}_{2}$ to be minimal unless the dust makes up $20 \%$ or more of the layer. Using a bulk value of $50 \% \mathrm{CO}_{2}$ for the layered deposits as a whole, we estimate the $\mathrm{CO}_{2}$ required as $2.5 \times 10^{6} \mathrm{~km}^{3}$ or $2.5 \times 10^{21} \mathrm{~cm}^{3}$ (from rough calculations of layered deposit volume by Cutts, 1973b). The present atmosphere of Mars contains about $2 \times 10^{19} \mathrm{~cm}^{3}$ (Murray and Malin, $1973 \mathrm{~b}$ ), so approximately 100 times as as much solid $\mathrm{CO}_{2}$ must be, or must have been, stored in the layered deposits. Leighton and Murray (1966) and Murray and Malin (1973b) make a strong argument that a solid phase is acting as a reservoir of $\mathrm{CO}_{2}$ beneath the north polar cap, although this view has been challenged by Ingersoll (1974). They postulate a reservoir of $10^{20} \mathrm{~cm}^{3}$, indicating a total outgassing of $\mathrm{CO}_{2}$ of $60 \mathrm{~g} \mathrm{~cm}^{-2}$ of the planet's surface area. Our estimate requires a $\mathrm{CO}_{2}$ outgassing of approximately $1.5 \mathrm{~kg} \mathrm{~cm}^{-2}$, and for comparison the figure for the Earth is about $70 \mathrm{~kg} \mathrm{~cm}^{-2}$. While we see no violation of factual observations by this amount of outgassing, it clearly implies a different history of differentiation and devolatilization than the Murray and Malin model. It also suggests that the ratio of $\mathrm{H}_{2} \mathrm{O}: \mathrm{CO}_{2}$ outgassed is lower on Mars than on Earth.

The second important assumption is that buried $\mathrm{CO}_{2}$ deposits will be under vapor pressures far above $6 \mathrm{mbars}$, and therefore much more stable than recent authors have accepted (Murray and Malin, 1973b; Ingersoll, 1974). Ingersoll argued that a buried $\mathrm{CO}_{2}$ deposit is unstable because the average annual temperature at the surface above the deposit is higher than the $\mathrm{CO}_{2}$ saturation temperature. This is true because the winter temperature, during which frost is deposited at the poles, is apparently the temperature corresponding to the $6 \mathrm{mbar}$ atmospheric pressure. Since summertime temperatures are higher, the average temperature is above the $6 \mathrm{mbar}$ temperature $\left(148^{\circ} \mathrm{K}\right)$. If the surface tem- perature is high, then the buried deposit receives a net influx of heat and must begin to sublimate if it is in vapor contact with the atmosphere. Hence, such a buried deposit is not stable.

Such an argument does not apply to deposits of $\mathrm{CO}_{2}$ which are effectively sealed from the atmosphere. Since dust and fine particles of water-ice frost are likely to form a blanket with very low permeability, we can expect buried $\mathrm{CO}_{2}$ to build up appreciable vapor pressure before significant escape to the atmosphere begins. Given an average surface temperature of $180^{\circ} \mathrm{K}$, only 200 mbars pressure is required to stop sublimation. In fact, if vapor pressures equaled the overburden pressure, then the triple point pressure (5.1 bars) would be reached at a depth of less than $100 \mathrm{~m}$, and neither sublimation nor melting would occur until the temperature rose to $217^{\circ} \mathrm{K}$.

Murray and Malin (1973b) consider the burial of solid $\mathrm{CO}_{2}$ to be unlikely because of the warming effect of dust being deposited at the same time. It seems necessary to postulate a climate somewhat different from today's climate to allow such deposition, but in view of the fact that the polar deposits now appear to be eroding, a different (perhaps colder and cloudier) climate must have been present in the past just to explain the existence of the polar deposits at all. The changed conditions might have been due to obliquity oscillations, as suggested by Ward (1974), or to other unknown causes (e.g., periods of active volcanism which changed insolation).

Two bits of observational data suggest the possibility that $\mathrm{CO}_{2}$ might be present in buried deposits at the pole. First, the ratio of mass of known $\mathrm{CO}_{2}$ outgassed on Mars to the planet's weight, approximately $4 \times 10^{-8}$, is far less than that of Earth (including carbonates), or Venus, near $10^{-4}$ (Ingersoll, 1974). One effective way to account for a much larger amount of outgassed $\mathrm{CO}_{2}$ is to postulate large quantities sealed in the polar deposits. Second, a plausible explanation for the unusual erosion features observed near the poles (Sharp, 1973; Cutts, 1974) is that wind erosion of overlying dust caused 
pressure reductions at depth and the consequent sublimation of buried $\mathrm{CO}_{2}$.

A final assumption is that the temperature gradient with depth is sufficiently steep that most $\mathrm{CO}_{2}$ layers below the first few hundred meters are considerably warmer than the $150^{\circ} \mathrm{K}$ winter temperature at the surface. The existence of reasonably young volcanic activity supports the contention of a positive gradient that might be quite steep. Sagan (1973) speculated that it might be equivalent to the Earth's gradient, $10-40^{\circ} \mathrm{K} \mathrm{km}^{-1}$. Even a $10^{\circ}$ gradient would bring $\mathrm{CO}_{2}$ near its melting point at the maximum $6 \mathrm{~km}$ depths for the base of the present layered deposits postulated by Cutts (1973b). However, such a gradient would be slow enough in developing that it does not seriously jeopardize our earlier suggestion of a $10-15 \mathrm{~km}$ thick pile of material at the pole before significant flow had occurred.

\section{Conclusion}

The concept of "glaciation" on Mars remains an alternate working hypothesis for explaining the unique features of the polar deposits of Mars. Observational evidence is not diagnostic. The unusual topography of the permanent ice caps at both poles strongly suggests flow in the underlying layered deposits. The fine layering of the layered deposits is compatible with a flow interpretation, but sedimentary interpretations are more conventional. The overall shape and thickness of the deposits are well explained by flattening of a thick $\mathrm{CO}_{2}$-rich sheet, but they could also have been deposited fortuitously with similar dimensions. Good evidence of flow patterns in the layered deposits, large enough to be visible in the Mariner 9 television pictures, are lacking. However, considerations of the physics of such a mechanism are favorable. We have shown that $\mathrm{CO}_{2}$ does indeed flow at low stresses, and further assumptions needed to construct a plausible model are indeed reasonable.

Because the flow hypothesis carries new and different implications from other hypotheses used to explain the history of the
Martian polar regions, the constraints on the atmospheric history and devolatilization of the planet are not at all clear. Thus one should maintain caution when accepting specific constraints based on the polar history of Mars and building atmospheric or planetary differentiation models upon these constraints.

\section{ACKNowledgments}

The authors are grateful to C. Drexler, J. Baily, and D. Chapman for their help with experimental problems; to Dr. D. R. Peacor for discussions of mineralogical problems; and to Dr. C. I. Smith for encouragement in the early stages of the study. Drs. J. A. Cutts and R. P. Sharp contributed unsettling but appreciated discussions and reviews. The illustrations were prepared by D. Bell. Financial support was provided by the National Aeronautics and Space Administration, Grant No. NRG 23-005-563. Finally the authors thank the management of the Chemetron Corporation, Toledo, Ohio, for providing the information on the commercial preparation of the $\mathrm{CO}_{2}$ used.

\section{REFERENCES}

Belcher, D., Veverka, J., and Sagan, C. (1971). Mariner photography of Mars and aerial photography of Earth: Some analogies. Icarus 15, 241.

Cutrs, J. A. (1973a). Wind erosion in the Martian polar regions. J. Geophys. Res. 78, 4211.

Cutrs, J. A. (1973b). Nature and origin of layered deposits of the Martian polar regions. $J$. Geophys. Res. 78, 4231.

Cutrs, J. A. (1974). Mars: Landforms of the South Polar Region (abst.). EOS 56, 1142.

Dzcrisin, D., and Blasics, K. R. (1975). Topography of the polar layered deposits of Mars. J. Geophys. Res. 80, 3286.

Grev, J. W. (1955). The creep of polycrystalline ice. Proc. Roy. Soc. London, Ser. A. 228, 519.

Hooke, R. Le B., Dahlin, B. B., ANd Kauper, M. T. (1972). Creep of ice containing dispersed fine send. J. Glaciology 11, 327.

Ivgersoll, A. P. (1974). Mars: The case against permanent $\mathrm{CO}_{2}$ frost caps. J. Geophys. Res. 79, 3403.

Klione, A. J., FJelbo, G., Seidel, B. L., SyKes, M. J., ANd Woiceshyn, P. M. (1973). $S$ Band radio occulation measurements of the atmosphere and topography of Mars with Mariner 9: Extended mission coverage of polar and intermediate latitude. J. Geophys. Res. 78, 4331. 
Leighton, R. B., and Murray, B. C. (1966). Behavior of $\mathrm{CO}_{2}$ and other volatiles on Mars. Science 153, 136.

Miller, S. L., AND Smythe, W. D. (1970). Carbon dioxide clathrate in the Martian ice cap. Science 170, 531 .

Murray, B. C., and Malin, M. C. (1973a). Polar wandering on Mars. Science 179, 997.

Murray, B. C., and Malin, M. C. (1973b). Polar volatiles on Mars: Theory vs. observations. Science 182, 432.

Murray, B. C., Soderblom, L. A., Cutts, J. A., Sharp, R. P., and Milton, D. (1972). A geological framework for the South Polar Region. Icarus 17, 328.

Nash, D. B. (1974). The relative age of the escarpments in the Martian polar laminated terrain based on morphology. Icarus 22, 385.

NYE, J. F. (1953). The flow law of ice from measurement in glacier tunnels, laboratory experiments and the Jungfraufirn borehole experiment. Proc. Roy. Soc. London, Ser. A 219, 477 .

Orowas, E. (1949). The flow of ice and other solids (discussion). J. Glaciology 1, 231.
Rigsby, G. P. (1y58). Effoct of hydrostatic pressure on velocity of shear deformation of single ice crystals. $J$. Glaciology, 3, 273.

Sagan, C. (1973). Liquid carbon dioxide and the Martian polar laminas. J. Geophys. Res. 78, 4250 .

Sharp, R. P. (1973). Mars: South Polar pits and etched terrain. J. Geophys. Res. 78, 4222.

Sharp, R. P. (1974). Ice on Mars. J. Glaciology $13,173$.

Sherby, O. D., ANd Burke, P. M. (1967). Mechanical behavior of crystalline solids at olevated temperature. Progr. Math. Sci. 13, 325.

Soderblom, L. A., Kreidler, T. J., AND Masursky, H. (1973a). Latitudinal distribution of a debris mantle on the Martian surface. J. Geophys. Res. 78, 4117.

Soderblom, L. A., Marin, M. C., Cutts, J. A., axd Murray, B. C. (1973b). Mariner 9 observations of the surface of Mars in the North Polar region. J. Geophys. Res. 78, 4197.

WARD, W. R. (1974). Climatic variations on Mars 1. Astronomical theory of insolation. $J$. Geophys. Res. 79, 3375. 